\title{
Desorption-induced first-order phase transition in a cyano-bridged compound
}

\author{
Y. Moritomo, ${ }^{1, a)}$ F. Nakada, ${ }^{1}$ H. Kamioka, ${ }^{1}$ J. E. Kim, ${ }^{2}$ and M. Takata ${ }^{3}$ \\ ${ }^{1}$ Department of Physics, University of Tsukuba, Tsukuba 305-8571, Japan \\ ${ }^{2}$ JASRI/SPring-8, 1-1-1 Kouto, Sayo-cho, Sayo-gun, Hyogo 679-5198, Japan \\ ${ }^{3}$ RIKEN/SPring-8, 1-1-1 Kouto, Sayo-cho, Sayo-gun, Hyogo 679-5148, Japan
}

(Received 20 February 2008; accepted 20 March 2008; published online 8 April 2008)

\begin{abstract}
The guest-host interaction is one of the promising tools to control the material state. Here, we found that a cyano-bridged compound $\mathrm{Na}_{0.50} \mathrm{Co}\left[\mathrm{Fe}(\mathrm{CN})_{6}\right]_{0.72} 3.8 \mathrm{H}_{2} \mathrm{O}$ shows a first-order structural phase transition below a critical pressure $P_{c}(150 \mathrm{~Pa})$ at $300 \mathrm{~K}$. Judging from suppression of the $\mathrm{OH}$ stretching mode in the infrared spectra, we ascribed the phase transition to desorption of the ligand waters. The phase transition accompanies a significant change of the visible absorption spectra, reflecting the strong hybridization between the $\mathrm{Co} e_{g}$ state and the $\mathrm{CN} \sigma$ states. (C) 2008 American Institute of Physics. [DOI: 10.1063/1.2908049]
\end{abstract}

Recently, nanoporous compounds are attracting the interest of materials scientists because the nanospaces of the host compound can be utilized as storage of the guest molecules, such as $\mathrm{O}_{2}, \mathrm{H}_{2} \mathrm{O}$, NO, and so on. ${ }^{1}$ In an extreme case, the low-dimensional alignment of the nanospaces induces an interesting physical property of the guest molecules. For example, one-dimensional arrangement of $\mathrm{O}_{2}$ within the framework of a copper coordination polymer, $\left[\mathrm{Cu}_{2}(\mathrm{pzdc})_{2}(\mathrm{pyz})\right]_{n}$, causes a spin gap behavior. ${ }^{2}$ Another significant feature of the nanoporous material is the guest-host interaction, which may change the lattice structure ${ }^{3}$ as well as the electronic and magnetic properties of the host system. In this letter, we report the desorption-induced first-order phase transition of the host framework in a cyano-bridged transition metal compound.

The cyano-bridged compound, $\mathrm{Na}_{x} \mathrm{Co}\left[\mathrm{Fe}(\mathrm{CN})_{6}\right]_{y} z \mathrm{H}_{2} \mathrm{O}$, is a nanoporous material. The compound consists of a threedimensional host framework, $-\mathrm{NC}-\mathrm{Fe}-\mathrm{CN}-\mathrm{Co}-\mathrm{NC}-$, and the guest species, that is, alkaline metals and waters. A part of the waters locates at the $\left[\mathrm{Fe}(\mathrm{CN})_{6}\right]$ vacancies and coordinates the Co ion (ligand water). The residual waters (zeolite water) and the alkaline metals locate in the nanospaces of the host framework. A significant feature of the cyano-bridged compound is the controllability of the guest concentration by electrochemical process, ${ }^{4}$ humidity ${ }^{5}$ and so on. Especially, the valence state of the transition metal can be tuned by the $\mathrm{Na}$ concentration $(x)$, analogous to the case of the chemical hole doping in the transition metal oxides. The Co-Fe compound is attracting the interest of material scientists because it shows the photoinduced magnetization ${ }^{6,7}$ and the photoinduced structural change. ${ }^{8}$

Films of the $\mathrm{Co}-\mathrm{Fe}$ compound were electrochemically synthesized on indium tin oxide (ITO) transparent electrodes (sheet resistance was $100 \Omega$ ) under potentiostatic condition at $-0.5 \mathrm{~V}$ versus a standard $\mathrm{Ag} / \mathrm{AgCl}$ electrode in an aqueous solution containing $0.5 \mathrm{mmol} / 1 \quad \mathrm{~K}_{3}\left[\mathrm{Fe}^{\mathrm{II}}(\mathrm{CN})_{6}\right]$, $1.25 \mathrm{mmol} / 1 \mathrm{Co}\left(\mathrm{NO}_{3}\right)_{2}$, and $1 \mathrm{~mol} / 1 \mathrm{Na}\left(\mathrm{NO}_{3}\right)$. The elemental analysis by the inductively coupled plasma method and a CNH organic elementary analyzer (Perkin-Elmer 2400 CHN Elemental Analyzer) yields $\mathrm{Na}_{0.88} \mathrm{Co}\left[\mathrm{Fe}(\mathrm{CN})_{6}\right]_{0.70}$

${ }^{a)}$ Electronic mail: moritomo@sakura.cc.tsukuba.ac.jp.
$3.8 \mathrm{H}_{2} \mathrm{O}(x=0.88)$. The film thickness was about $500 \mathrm{~nm}$, which was determined by the cross-sectional scanning electron microscope image. We further control $x$ by the oxidization process of the film at $0.5-0.7 \mathrm{~V}$ versus a standard $\mathrm{Ag} / \mathrm{AgCl}$ electrode in $1 \mathrm{~mol} \mathrm{Na}\left(\mathrm{NO}_{3}\right)$ aqueous solution. Here, we found that $x$ decreases in proportion to the total charge (electrons/Co site) flown in the oxidation process, while the $\left[\mathrm{Fe}(\mathrm{CN})_{6}\right]$ concentration $(y=0.69-0.72)$ and the water concentration $(z=0.38)$ are nearly unchanged. The chemical composition of the films are $\mathrm{Na}_{0.50} \mathrm{Co}$ $\left[\mathrm{Fe}(\mathrm{CN})_{6}\right]_{0.72} 3.8 \mathrm{H}_{2} \mathrm{O} \quad(x=0.50)$ and $\mathrm{Na}_{0.30} \mathrm{Co}\left[\mathrm{Fe}(\mathrm{CN})_{6}\right]_{0.72}$ $3.8 \mathrm{H}_{2} \mathrm{O}(x=0.30)$. The $\mathrm{x}$-ray powder diffraction patterns are consistent with the face-centered cubic, the lattice constant is $1.03024(1) \mathrm{nm}$ at $x=0.88$ and $1.02769(1) \mathrm{nm}$ at $x=0.50$. The film color changes from transparent green to red with the decrease of $x$.

Figures 1 show the absorption spectra of these films in (a) infrared and (b) visible region. In the as-grown film $(x=0.88)$, an intense absorption band is observed at $2080 \mathrm{~cm}^{-1}$, which is ascribed to the stretching vibration of the $\mathrm{CN}$ moiety sandwiched by the low-spin $\mathrm{Fe}^{\mathrm{II}}$ and the highspin $\mathrm{Co}^{\mathrm{II}} .{ }^{9}$ In the fullyoxidized film $(x=0.30)$, an absorption band is observed at $2120 \mathrm{~cm}^{-1}$, which is due to the $\mathrm{CN}$ moiety sandwiched by the low-spin $\mathrm{Fe}^{\mathrm{II}}$ and the low-spin $\mathrm{Co}^{\mathrm{III}}{ }^{10}$ In the intermediate film $(x=0.50)$, the absorption consists of two bands [see the least square-fitted broken curve of Fig.

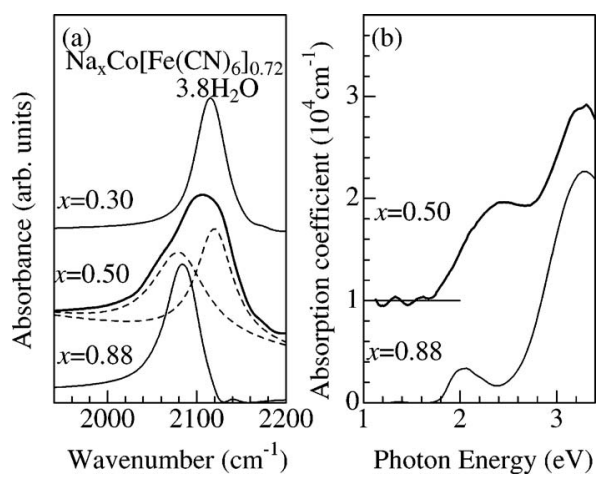

FIG. 1. (a) Infrared absorption spectra of $\mathrm{Na}_{x} \mathrm{Co}\left[\mathrm{Fe}(\mathrm{CN})_{6}\right]_{0.72} 3.8 \mathrm{H}_{2} \mathrm{O}$. Broken curves are the result of the least-square-fitting with two Lorentz functions. (b) Visible absorption spectra of $\mathrm{Na}_{x} \mathrm{Co}\left[\mathrm{Fe}(\mathrm{CN})_{6}\right]_{0.72} 3.8 \mathrm{H}_{2} \mathrm{O}$. 


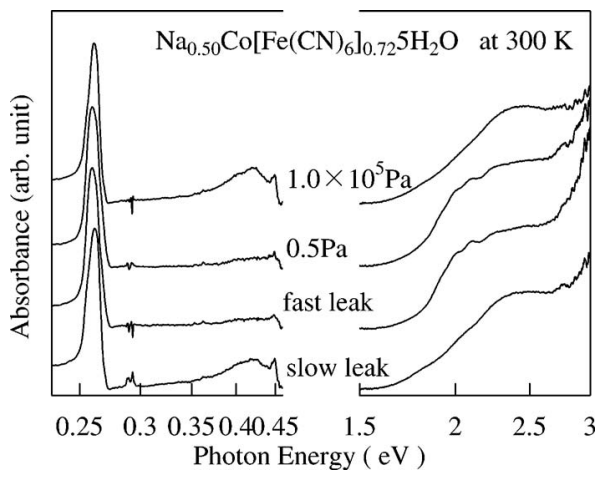

FIG. 2. Infrared and visible absorption spectra of $\mathrm{Na}_{0.50} \mathrm{Co}\left[\mathrm{Fe}(\mathrm{CN})_{6}\right]_{0.72} 3.8 \mathrm{H}_{2} \mathrm{O}$ under various pressure conditions. A downward arrow indicates the $\mathrm{OH}$ stretching band. A broken curve in the left panel is the differential spectra between the ambient pressure spectrum and the vacuum spectrum.

1(a)], which indicates the coexistence of the low-spin $\mathrm{Co}^{\mathrm{III}}$ and the high-spin $\mathrm{Co}^{\mathrm{II}}$. The valence modification also changes the visible absorption spectra. At $x=0.88$ [Fig. 1(b)], the spectra consists of the intense $3.2 \mathrm{eV}$ band and the weak $2.0 \mathrm{eV}$ band. At $x=0.50$, however, the $2.0 \mathrm{eV}$ band disappears and a much stronger band appears at $2.4 \mathrm{eV}$. Ohkoshi et $a .^{5}$ reported a similar $2.0 \mathrm{eV}$ band in $\left(\mathrm{Co}_{0.41}^{\mathrm{II}} \mathrm{Mn}_{0.59}^{\mathrm{II}}\right)$ $\times\left[\mathrm{Cr}^{\mathrm{III}}(\mathrm{CN})_{6}\right]_{2 / 3} 4.2 \mathrm{H}_{2} \mathrm{O}$ and ascribed it to the intra-atomic $d-d$ transition of the four-coordinate tetrahedral $\mathrm{Co}^{\mathrm{II}}$ site. On the other hand, the stronger $2.4 \mathrm{eV}$ band at $x=0.50$ is ascribed to the charge-transfer excitation from the $\mathrm{Fe}^{\mathrm{II}}$ site to the $\mathrm{Co}^{\mathrm{III}}$ site. The $3.2 \mathrm{eV}$ band is insensitive to $x$ and is reasonably ascribed to the lignad-metal charge-transfer transition of $\left[\mathrm{Fe}^{\mathrm{II}}(\mathrm{CN})_{6}\right]$.

Figure 2 show the depressurization effect on the infrared and visible absorption spectra at $x=0.50$. The depressurization process significantly suppresses the $\mathrm{OH}$ stretching band at $0.43 \mathrm{eV}$ (see the downward arrow in Fig. 2), indicating that waters are desorbed in vacuum.

The depressurization process further induces the $2 \mathrm{eV}$ band, as seen in the differential spectrum (broken curve). These spectral changes are reversible in repeated pressurecycles (see the bottom spectra of Fig. 2). The desorption process of the water molecules takes a few minutes, while the adsorption process takes a few hours. We investigated the depressurization effect on the electronic state of the Fe and Co ions by means of the $\mathrm{x}$-ray absorption near edge structure (XANES) around the $K$-edge region at $300 \mathrm{~K}$ and found that only the Co spectrum shows a detectable change. Therefore, we ascribed the desorption-induced $2 \mathrm{eV}$ band to the intraatomic $d-d$ transition of the $\mathrm{Co}^{\mathrm{II}}$ site and call the band as "Co ${ }^{\mathrm{II}}$ band."

To quantitatively investigate the depressurization effect on the spectral change, we measured the spectra at each pressure in the pressure-increasing run. The respective spectrum was measured after waiting for 5-10 min. We plotted in Fig. 3 the pressuredependence of the spectral weights for (a) the $\mathrm{Co}^{\mathrm{II}}$ band $\left(I_{\mathrm{Co}}\right)$, (b) the $\mathrm{OH}$ stretching band $\left(I_{\mathrm{OH}}\right)$, and $(\mathrm{c})$ the two $\mathrm{CN}$ stretching bands $\left(I_{\mathrm{CN}}\right)$. The magnitude of $I_{\mathrm{Co}}$ remains nearly constant $(\sim 0.75)$ below $10 \mathrm{~Pa}$ and then steeply decreases to $\sim 0.3$. The reduction of $I_{\mathrm{Co}}$ is completed at a critical pressure $P_{\mathrm{c}}(150 \mathrm{~Pa})$, showing a kink structure. Similar kink structures are observed in the $P-I_{\mathrm{OH}}$ curve [Fig. 3(b)] and the two $P-I_{\mathrm{CN}}$ curves [Fig. 3(c)] as indicated by the

In conclusion, we observed vacuum-induced phase
broken straight lines.
Downloaded 08 May 2008 to 130.158.56.186. Redistribution subject to AlP license or copyright; see http://apl.aip.org/apl/copyright.jsp

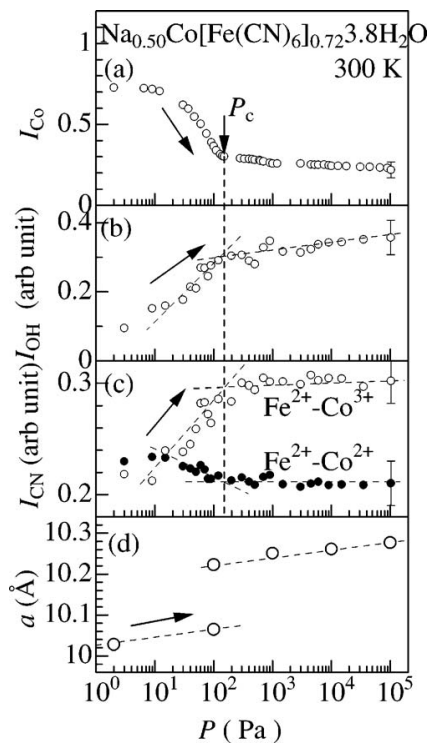

FIG. 3. Pressure dependence of the spectral weights for (a) the $\mathrm{Co}^{\mathrm{II}}$ band $\left(I_{\mathrm{Co}}\right)$, (b) the OH stretching band $\left(I_{\mathrm{OH}}\right)$, and (c) the two CN stretching bands $\left(I_{\mathrm{CN}}\right)$ in $\mathrm{Na}_{0.50} \mathrm{Co}\left[\mathrm{Fe}(\mathrm{CN})_{6}\right]_{0.72} 3.8 \mathrm{H}_{2} \mathrm{O}(x=0.50)$. (d) Pressure-dependence of the lattice constant $a$. The intensity of the $\mathrm{Co}^{\mathrm{II}}$ band is normalized by that at $x=0.88$. Broken straight lines are merely the guide for the eyes.

We further investigated the depressurization effect on the structure. In this measurement, the film was carefully removed from the ITO glass with a microspatula and then the ground fine powders were filled into the $0.1 \mathrm{~mm} \phi$ glass capillary. The capillary was depressurized at $2 \mathrm{~Pa}$ for $30 \mathrm{~min}$ and then kept at the respective pressure for 30-60 min to reach an equilibrium state. Then, the capillary was sealed up and was put on a Debye-Scherrer camera at the BL02B2 beamline ${ }^{11}$ of SPring-8. The lattice constant $a$ was refined by the Rietveld method, and was plotted in Fig. 3(d). With increase of pressure beyond $100 \mathrm{~Pa}, a$ discontinuously increases from $1.006 \mathrm{~nm}$ to $1.022 \mathrm{~nm}$. We emphasize that the small- $a$ phase (volume fraction is 0.37 ) and the large- $a$ phase (0.63) coexists at $100 \mathrm{~Pa}$. Thus, the desorption-induced phase transition is of the first-order, accompanying a significant structural change.

We think that the ligand waters play an essential role on the phase transition and the spectral change. First of all, appearance of the $\mathrm{Co}^{\mathrm{II}}$ band can be ascribed to the asymmetric ligand field around the $\mathrm{Co}^{\mathrm{II}}$ site. In the $\mathrm{Fe}-\mathrm{Co}$ cyanide, the $e_{g}$ orbital strongly hybridized with the $\sigma$ state of the ligands, that is, $\mathrm{CN}$ and $\mathrm{H}_{2} \mathrm{O} .{ }^{12}$ Then, if the ligand waters are removed, the $d-d$ transition of $\mathrm{Co}^{\text {II }}$ becomes dipole-allowed via the strong $d-\sigma$ hybridization. Secondly, the ligand waters bear a part of the host framework. Then, desorption of the ligand waters causes reduction of the cell parameter. We, however, need a cooperative mechanism to explain the firstorder nature of the phase transition. A most plausible mechanism may be the spin state transition of the $\mathrm{Co}^{\mathrm{II}}$ site from the high-spin state $(S=3 / 2)$ to the low-spin state $(S=1 / 2)$. We measured the temperature dependence of the magnetic susceptibility of the sample sealed in the glass capillary and estimated the effective moment $\mu_{\text {eff }}$. The magnitude of $\mu_{\text {eff }}$ decreases from $3.67 \mu_{B} / \mathrm{Co}$ at ambient pressure to $2.93 \mu_{B} / \mathrm{Co}$ at $3 \mathrm{~Pa}$. This observation supports the idea of the spin state transition.

In conclusion, we observed vacuum-induced phase 
transition $\left(P_{c}=150 \mathrm{~Pa}\right)$ at $300 \mathrm{~K}$ in $\mathrm{Na}_{0.50} \mathrm{Co}\left[\mathrm{Fe}(\mathrm{CN})_{6}\right]_{0.72}$ $3.8 \mathrm{H}_{2} \mathrm{O}$. The phase transition is of the first-order and accompanies a significant spectral change in the visible region. Such a property can be utilized as the simple pressure marker. A systematic investigation with changing $\mathrm{Na}$ concentration $(x)$, which is in progress, is significant to finely control the critical pressures.

This work was supported by a Grant-In-Aid for Scientific Research from the Ministry of Education, Culture, Sports, Science and Technology of Japan and the Japan Science and Technology Agency (CREST "X-ray Pinpoint Structural Measurement-Development of the Spatial- and Time-resolved Structural Study Technique for Nanomaterials and Devices"). We are grateful to Dr. Ohsawa for his help in the XANES spectroscopy. The synchrotronradiation $\mathrm{X}$-ray powder diffraction experiments were performed at the SPring-8 BL02B2 beamline with approval of the Japan Synchrotron Radiation Research Institute (JASRI).
${ }^{1}$ S. Kitagawa, R. Kitaura, and S. Noro, Angew. Chem., Int. Ed. 43, 2334 (2004).

${ }^{2}$ R. Kitaura, S. Kitagawa, Y. Kubota, T. C. Kobayashi, K. Kindo, Y. Mita, A. Matsuo, M. Kobayashi, H.-C. Chang, T. C. Ozawa, M. Suzuki, M. Sakata, and M. Takata, Science 298, 2358 (2002).

${ }^{3}$ O. M. Yaghi and H. Li, J. Am. Chem. Soc. 118, 295 (1996).

${ }^{4}$ O. Sato, Y. Einaga, T. Iyoda, A. Fujishima, and K. Hashimoto, J. Phys. Chem. B 101, 3903 (1997).

${ }^{5}$ S. Ohkoshi, K. Arai, Y. Sato, and K. Hashimoto, Nat. Mater. 3, 857 (2004).

${ }^{6}$ O. Sato, T. Iyoda, A. Fujishima, and K. Hashimoto, Science 272, 704 (1996).

${ }^{7}$ O. Sato, Y. Einaga, T. Iyoda, A. Fujishima, and K. Hashimoto, J. Electrochem. Soc. 144, L11 (1997).

${ }^{8}$ M. Hanawa, Y. Moritomo, A. Kuriki, J. Tateishi, K. Kato, M. Takata, and M. Sakata, J. Phys. Soc. Jpn. 72, 987 (2003).

${ }^{9}$ E. Reguera, J. F. Bertran, C. Diaz, and J. Blanco, Hyperfine Interact. 53, 391 (1990).

${ }^{10}$ O. Sato, Y. Einaga, A. Fujishima, and K. Hashimoto, Inorg. Chem. 38, 4405 (1999).

${ }^{11}$ E. Nishibori, M. Takata, K. Kato, M. Sakata, Y. Kubota, S. Aoyagi, Y. Kuroiwa, and M. Yamakawa, Nucl. Instrum. Methods Phys. Res. A 467468, 1045 (2001).

${ }^{12}$ T. Kawamoto, Y. Asai, and S. Abe, Phys. Rev. B 60, 12990 (1999). 